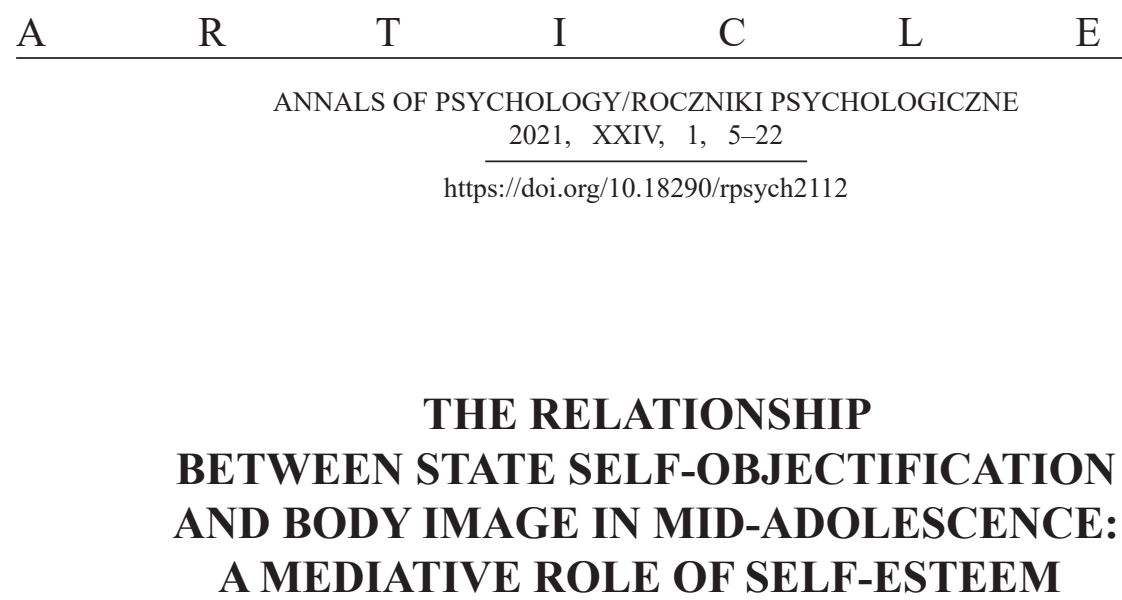

\author{
Beata Mirucka and Monika Kisielewska \\ Faculty of Education, University of Białystok
}

This paper investigates the impact of state self-objectification on body image and tests the role of self-esteem in this relationship. The study group consisted of 136 adolescents from a junior high school in Poland, aged 14 to 16 years: 65 boys $\left(M_{\text {age }}=15 ; S D=0.79\right)$ and 71 girls $\left(M_{\text {age }}=14.93 ; S D=0.82\right)$. Both age groups were relatively homogeneous in terms of demography and BMI. The study consisted of three phases. First, the participants completed demographic measures assessing demographic variables, body image, and self-esteem. The second phase was conducted one week later to induce a temporary state of self-objectification by means of a magnifying mirror. The third phase followed a ten-minute experimental exposure by filling in the Self-Objectification State Questionnaire. A mediation analysis was performed separately in both adolescent groups, according to the approach proposed by Hayes and Preacher (2014). Self-esteem mediated significantly the relationship between state self-objectification and body image. In the group of girls the mediation model produced a complete effect, whereas in the group of boys the mediation effect was partial.

Keywords: self-esteem; body image; self-objectification; mid-adolescence; mediation.

BeAta Mirucka, https://orcid.org/0000-0002-3903-1280; MoniKa KisielewsKa, https://orcid.org/0000-0002-5221-1649. Correspondence concerning this article can be addressed to Beata Mirucka, Uniwersytet w Białymstoku, Wydział Nauk o Edukacji, ul. Świerkowa 20, 15-328 Białystok, Poland; e-mail: b.mirucka@uwb.edu.pl.

Handling editor: WacŁaW BĄK, John Paul II Catholic University of Lublin. Received 29 June 2020. Received in revised form 19 Nov. 2020, 8 March 2021, 22 March 2021. Accepted 25 March 2021. Published online 2 June 2021. 
Adolescents experience very intensely the development of their physical body, which entails significant changes in the entire system of mental body representations (Assaiante et al., 2014), especially in the body image (Cash \& Pruzinsky, 2002). The change of body proportions and the development of secondary sex characteristics bring about a transformation from a child's body to an adult female/male body and deliver many new bodily sensations, which in turn results in significant changes of body image representation (Cash \& Pruzinsky, 2002).

At the same time teenagers are hugely influenced by the factors originating in the sociocultural realm. Unfortunately, many such factors produce a negative impact on the formation of mental body representations, of which self-objectification (Fredrickson \& Roberts, 1997; McKinley \& Hyde, 1996) has been omnipresent in the Western culture, especially via the mass media (Karsay et al., 2018). The Internet, the movies, advertisements, TV programs and magazines all universally and insistently present unrealistic figures as beauty ideals. These ideal pictures of the human body (both male and female) induce appraisals of one's appearance, leading to negative emotions (e.g., shame and anxiety) (Dakanalis et al., 2015). The most sinister outcome of this process is internalization of external perspectives into one's own physical self and a resulting crucial change in self-consciousness that is characterized by a habitual self-monitoring of one's body. It means that both genders perceive their bodies from a third person perspective (as an object) and consequently value themselves mainly for the external attributes of the body (Fredrickson \& Roberts, 1997).

Adolescents are particularly vulnerable to self-objectification (Fredrickson \& Roberts, 1997; Martin \& Gentry, 1997), which makes their experience of their teenage bodies very unfavourable and produces a distorted body image. Therefore, the search for factors that protect body image against this threat becomes urgent. Global self-esteem is a crucial factor in maintaining numerous positive psychosocial states like well-being, effective coping strategies, and successful relationships with others (Kuster et al., 2013; Orth et al., 2012). There are a number of studies indicating a significant positive relationship between body image and self-esteem (Morin et al., 2011; Paxton et al., 2006). Could it be predicted, therefore, that self-esteem protects the teenagers' body image against self-objectification? The present study aims to explore the relationship between a state of self-objectification and body image representation and, above all else, investigates the role of self-esteem as a protector of body image against the consequences of self-objectification in mid-adolescents. 


\section{Body Image in Adolescence}

During adolescence, a significant body transformation takes place. The teenage body gains feminine or masculine attributes, and its proportions and appearance change. These bodily changes lead to the intensive preoccupation of girls and boys with their changing looks (Smolak, 2004), which is reflected in transformations in their body image. Body image refers mainly (but not exclusively) to exteroception and constitutes a system of mental representations, including perceptions, beliefs, and emotions directed towards the body. This relates to the manner of perceiving one's body, particularly in the context of physical appearance (Gallagher, 2005).

During adolescence, many factors impact a developing body image, including cultural, interpersonal, and individual ones, with gender being the variable that diversifies the development of this body representation in the most significant degree (Golan et al., 2014). Both male and female adolescents are particularly preoccupied with their bodies (Smolak, 2004) and usually evaluate them negatively (Eisenberg et al., 2006; Knauss et al., 2008), with girls experiencing a greater dissatisfaction with their appearance or body weight more often (Kostanski et al. 2004; Kostanski \& Gullone, 2007).

The development of body representation, although it is based on various stimuli coming from the body and its perception, always takes place in relation to someone who gives meaning to these bodily signals and percepts. Initially it is shaped in the relationship with a caregiver (Krueger, 2002; Mirucka, 2018a) and is later influenced by other people, society, and culture (significant others). In the period of adolescence, the impact of caregivers is still present, but it is gradually replaced by peer influence (Duarte \& Pinto-Gouveia, 2017), the mass media (Rousseau \& Eggermont, 2018) and other factors derived from the sociocultural realm. In their self-objectification theory, Fredrickson and Roberts (1997) point to the fact that the self is a social construct and that the manner in which the society treats individuals bears on the way individuals treat themselves. This emphasizes the role of the quality of messages present in the sociocultural space in the shaping of body image. If these messages convey the natural proportions and appearance of the body in a positive light, they can enhance a positive body experience (Mirucka, 2018b). However, if - as is usually the case in contemporary culture - they show unnaturally thin and sexualized figures as ideals of beauty (Vandenbosch \& Eggermont, 2015), they can disturb the relationship of the individual with their own body and lead to its objectification and eventually to a distorted body image. 


\section{Self-Objectification in Adolescents}

Self-objectification is a multi-step process (Vandenbosch \& Eggermont, 2015) in which individuals begin to treat themselves and their bodies as objects, while losing contact with their experiences, emotions, and needs. The root cause of this phenomenon lies in the contemporary Western culture which makes physical appearance a source of attractiveness and value (the so-called "culture of physical appearance"). This objectifying culture compels people to develop a self-perception of external observers, which causes them to engage more in "external existence" than in self-experiencing (Fredrickson \& Roberts, 1997; McKinley \& Hyde, 1996). The societal standards of attractiveness can be transmitted to teenagers via different agents, most notably the media, but also parents and peers (e.g., Jones et al., 2004).

Self-objectification involves three steps: (a) an internalization of the media or (societal) appearance ideals, (b) valuing appearance over competence, and (c) running a continuous body surveillance (Roberts, 2012; Vandenbosch \& Eggermont, 2012). Studies on adolescents confirm the relationship between these variables. Teenage girls (aged 10 to 15) with higher levels of internalized media-promoted standards of beauty and attractiveness showed higher levels of body surveillance (McKenney \& Bigler, 2016). Also, a sexualizing media exposure intensified media internalization, which in turn leads to higher levels of self-objectification and body surveillance (Vandenbosch \& Eggermont, 2012). The key step in the process is a possible internalization of external norms in self-evaluation and replacing one's own beliefs with societal ones. If a person considers the sociocultural norms of appearance as appropriate standards for their own appearance, then internalization can take place (Thompson \& Stice, 2001). It is very difficult to satisfy the current Western standards of attractiveness - the thin female ideal and the mesomorph male ideal, so a discrepancy between the internalized ideal and one's actual appearance results in body dissatisfaction (Rousseau \& Eggermont, 2017), which is so widespread that it is referred to as "normative discontent" (Rodin et al., 1984). If an adolescent adopts societal appearance ideals as their own standard of self-evaluation, the satisfaction or dissatisfaction with their body becomes a function of the extent to which one does (or does not) meet the internalized appearance ideal (Rousseau \& Eggermont, 2017). Body dissatisfaction concerns around $60 \%$ of girls and $30 \%$ of boys, which declare a desire to change the shape and size of their body. In $25 \%$ of girls this dissatisfaction reached the level of a clinical disorder (Knauss et al., 2008; Presnell et al., 2004).

Self-objectification can be triggered and reinforced by participating in situations where the person feels being watched and judged, which intensifies the intake of the observer's perspective (Noll \& Fredrickson, 1998). Experimental studies have shown various situations which enhance self-objectification, for instance viewing 
yourself in a mirror while wearing a bathing suit (Fredrickson et al., 1998; Hebl et al., 2004; Quinn et al., 2006) or exposure to words associated with objectification (e.g. "desired") (Roberts \& Gettman, 2004). In such situations, a person may experience the state of objectification that is a situationally induced state of treating oneself as an object under evaluation. The emergence of evaluative processes is associated with the real or imagined presence of people who are perceived as critical observers (Noll \& Fredrickson, 1998).

\section{Adolescents' Self-Esteem}

Self-esteem is an attitude towards the self, which can take a positive or negative orientation (Rosenberg, 1965). Positive global self-esteem is crucial in maintaining well-being, effective coping strategies, and successful relationships with others (Kuster et al., 2013; Ort et al., 2012). The mean level of self-esteem changes during the early periods of life: it is relatively high in childhood (Chung et al., 2017; Harter, 2012), decreases in adolescence (Chung et al., 2017; Orth \& Robins, 2014) and increases again in young adulthood (Chung et al., 2017; Orth \& Robins, 2014). This means that adolescence is a period of particular vulnerability to disturbances in self-esteem. More detailed analyses show gender differences in the decline in self-esteem. Female adolescents experience a significant drop in self-esteem (Baldwin \& Hoffmann, 2002), which explains, at least in part, their decreased body satisfaction (Clay et al., 2005). Male adolescents' self-esteem is more stable. A slight and short-lived decline appears from 14 to 16 years of age (Baldwin \& Hoffmann, 2002). Gender difference in this respect is the greatest during mid-adolescence and peaks at around 16 years of age (Kling et al., 1999).

Adolescents' self-esteem is anchored to some extent in the way the body is perceived and experienced. Studies in groups of male and female adolescents show a strong correlation between perceived appearance and self-esteem (Harter, 2012), but their trajectories are different. In the boys' group, high body satisfaction and self-esteem are provided by the sense of physical power connected with being tall and brawny. Thus all visible, pubertal changes are welcome, because they make the boys more satisfied with their bodies and, more generally, with themselves. In the girls' group, all changes such as larger hips or increased weight elevate body dissatisfaction and are conducive to low self-esteem (Gatti et al., 2014). For girls, body image constitutes a central reference point in the creation of self-definition. They have been socialized in the way that emphasizes appearance as an important reference in the process of self-evaluation and the evaluation by others (Thompson et al. 1999). Extraordinary changes in teenage appearance additionally heighten 
dissatisfaction with themselves. For example, congenital anomalies and acquired skin disorders have a negative impact on adolescents' self-esteem (Vivar \& Kruse, 2018). Is the opposite effect possible? Could self-esteem protect body image from negative external impacts?

\section{The Present Study}

This study is part of a wider research project on the body experience in mid-adolescents. In this paper we investigate the impact of state self-objectification on body image and test the role of self-esteem in this relationship. We predict that self-esteem is a mediator between the state of self-objectification and body image. Body dissatisfaction, which is anchored in the self-objectification process, affects adolescents' self-esteem (Kostanski \& Gullone, 1998), and self-esteem, in its turn, affects body image (Morin et al., 2011; Paxton et al., 2006). Hence, we test the following hypotheses:

H1: The participants - adolescent girls and boys - differ significantly in the self-objectification state and the representation of body image.

$\mathrm{H} 2$ : The relationship between state self-objectification and the representation of body image is mediated by self-esteem.

H3: In both groups the mediation effect of self-esteem is different.

\section{METHOD}

\section{Participants}

The study group consisted of 136 adolescents from a junior high school in Poland, aged 14 to 16 years: 65 boys $\left(M_{\text {age }}=15.00 ; S D=0.79\right)$ and 71 girls $\left(M_{\text {age }}=14.93 ; S D=0.82\right)$. Participation in the study was unpaid and voluntary. Both age groups were relatively homogeneous in demography and BMI terms $\left(M_{\text {boys }}=20.58 ; S D=3.71\right.$ and $M_{\text {girls }}=19.73 ; S D=2.55 ; t(130)=1.55 ; p=.120$; see Table 1). 
Table 1

Demographic and Clinical Data

\begin{tabular}{|c|c|c|}
\hline \multirow{2}{*}{ Demographic/Clinical data } & \multicolumn{2}{|c|}{ Surveyed boys and girls } \\
\hline & Boys $(n=65)$ & Girls $(n=71)$ \\
\hline \multicolumn{3}{|l|}{ Place of residence } \\
\hline$>25,000$ inhabitants & $52(80 \%)$ & $52(73.2 \%)$ \\
\hline$<25,000$ inhabitants & $5(7.7 \%)$ & $11(15.5 \%)$ \\
\hline Village & $8(12.3 \%)$ & $8(11.3 \%)$ \\
\hline \multicolumn{3}{|l|}{ BMI } \\
\hline Underweight $(<18.5)$ & $14(21.5 \%)$ & $19(26.8 \%)$ \\
\hline Normal (18.5-24.99) & $45(69.2 \%)$ & $48(67.6 \%)$ \\
\hline Overweight (25-29.99) & $3(4.6 \%)$ & $2(2.8 \%)$ \\
\hline Obese $(>30)$ & $3(4.6 \%)$ & $2(2.8 \%)$ \\
\hline
\end{tabular}

\section{Measures}

\section{Demographical and Psychological Variables}

Apart from standard questions, the Demographic Data Questionnaire (DDQ) also included queries about height and body weight, felt physical and mental discomfort, as well as questions regarding physical illness. The information was used to exclude those individuals whose health condition could have substantially affected research results.

\section{Body Image}

The Body Image Test (BIT) constitutes a part of the Battery of Tests of the Body Self Representations (Mirucka, 2017) and comprises 6 items. Statements are rated on a 7-point scale ranging from I totally disagree to I totally agree. The scale is one-dimensional, with separate versions for males and females, and has its own a priori key. An example of a BIT item: I would like to have a different body build. High scores in BIT mean the acceptance of one's own body, and a generally positive body image. Low scores prove dissatisfaction with one's own physical appearance, and experiencing the body as an obstacle in relations with others. The construction 
of scales was a multi-stage process completed according to the rules for creating psychological research tools based on advanced statistical procedures (Mirucka, 2017). The reliability of tests in the presented study was: $\alpha=.85$ for the girls $\alpha=.80$ for the boys.

\section{The State of Self-Objectification}

The Self-Objectification State Questionnaire (SOSQ) served to measure the intensity of temporary state of self-objectification induced by experimental manipulation with the use of a magnifying mirror. This questionnaire was created for the purposes of the present study. It comprised 10 statements rated on a 7-point scale ranging from I totally disagree to I totally agree. An example of a SOSQ item: "I started comparing myself to what I wanted to look like." High SOSQ scores signify the dissatisfaction with the body, activating the mechanisms of comparing oneself with others, a sense of being alien to oneself, and disorientation and confusion about one's own appearance. Low scores prove high body image stability, resistance to self-objectification processes and to dissatisfaction with one's own appearance. The reliability of the SOSQ in the present study turned out to be very high: $\alpha=.87$ in the girls' group and $\alpha=.89$ in the boys' group.

\section{General Self-Esteem}

The Rosenberg Self-Esteem Scale (SES; Rosenberg, 1965) is a tool used for a general assessment of self-esteem. It is made up of 10 diagnostic questions, which are marked on a 4-point scale. In our research a Polish SES adaptation by Łaguna et al. (2007) was used. This tool is characterized by a high degree of internal consistency: the Cronbach's alpha score is between .81 and .83 . The stability ratio of this tool, defined by using the test-retest method, is .50 (1-year period). The theoretical accuracy of the scale was validated based on an exploration and confirmation factor analysis. The reliability level achieved in the present study was: $\alpha=.91$ for girls and $\alpha=.87$ for boys.

\section{Procedure}

The presented research is a part of a wider experimental study. In the first phase of the study the participants were asked to fill in the questionnaire measures (DDQ, BIT, SES). The second phase was conducted one week later and aimed at inducing a temporary state of self-objectification. For this purpose, a magnifying mirror 
was used. Mirrors have previously been used in experimentally induced states of objectification (Fredrickson et al., 1998; Hebl et al., 2004; Quinn et al., 2006). In the present study we used a magnifying mirror of the following dimensions: $150 \mathrm{~cm}$ height, $66 \mathrm{~cm}$ width, the radius of curvature of about $350 \mathrm{~cm}$. The mirror slightly but noticeably widened the body without affecting its height. The participants were asked to stand at a distance of $150 \mathrm{~cm}$ from the mirror, placed $23 \mathrm{~cm}$ above the floor and tilted back about 2 degrees. Their task was to focus on particular areas of their reflection according to the instructions given from an audio recording. In order to eliminate possible distortion variables (the reader's gender), a female voice was presented in the group of girls, and a male voice in the group of boys. The content of the instructions drew the participants' attention to subsequent areas of their reflection in the mirror (sequence: whole body, arms, chest, stomach, thighs, calves) in a position with the face towards the mirror, as well as with one and the other side towards the mirror. After watching themselves from different sides the participants were asked to stand with their faces towards the mirror again, and to respond, in their minds, to questions such as: What is your shape? What size is your chest? What does your stomach look like? Neutral language was used intentionally to avoid wording which might foster dissatisfaction with the body. The duration of the experimental exposure was 10 minutes. Immediately afterwards, at the third stage of the research, the adolescents filled in the SOSQ. The last stage of the examination involved debriefing.

\section{RESULTS}

\section{Preliminary Analyses}

The differences in mean scores of body image representation between boys $M=22.65, S D=8.37)$ and girls $(M=17.51, S D=9.27)$ were statistically significant. The adolescent girls revealed considerably lower mean results than the boys: $t(134)=3.38, p<.001, d=.58$. Similarly, the girls reported significantly lower mean scores in self-esteem $(M=26.51, S D=6.29)$ than the boys $(M=30.51$, $S D=5.87): t(134)=3.82, p<.001, d=.65$. However, in relation to the variable of self-objectification state the mean scores were significantly higher in the girls group $(M=43.04 ; S D=12.27)$ than in the boys $(M=34.59, S D=13.82), t(133)=-3.76$, $p<.001, d=.64$.

Three pairs of variables were significantly correlated: (a) self-objectification state (SOS), (b) self-esteem (SE), and (c) body image (BI) (see Table 2). 
Table 2

Correlations of Variables of Interest in Group of Boys and Girls

\begin{tabular}{lcccccc}
\hline \multicolumn{1}{c}{ Variables } & \multicolumn{3}{c}{$\begin{array}{c}\text { Boys } \\
(n=65)\end{array}$} & & \multicolumn{3}{c}{$\begin{array}{c}\text { Girls } \\
(n=71)\end{array}$} \\
\hline & 1 & 2 & 3 & 1 & 2 & 3 \\
\cline { 2 - 7 } & - & $-.39^{* *}$ & $-.42^{* *}$ & - & $-.39^{* *}$ & $-.40^{* * *}$ \\
1. State self-objectification & & - & $.59^{* * *}$ & - & $.74^{* * *}$ \\
2. Self-esteem & & - & & & - \\
3. Body image & & & - & & & \\
\hline
\end{tabular}

$* * p<.01$.

In both groups the value of correlation between SOS and SE, as well between SOS and BI indicated a negatively moderate strength of relation. However, the correlation between SE and BI was highly positive for the girls and very highly positive for the boys.

\section{Main Analyses}

To verify the main hypotheses ( $\mathrm{H} 2$ and $\mathrm{H} 3$ ), a mediation analysis was carried out separately in both adolescent groups, according to the approach proposed by Hayes and Preacher (2014). We used the PROCESS macro 3.5 for SPSS (Hayes, 2019) to test for simple mediation. We applied the PROCESS Model 4 to assess the role of self-esteem as a mediator between the self-objectification state as an independent variable, and body image as a dependent variable. In our mediation analyses we followed Hayes (2017) instructions to test the indirect (mediated) pathway through 5,000 accelerated and bias-corrected bootstraps. In other words, we employed bootstrapping and confidence intervals to test the indirect effect of self-esteem. PROCESS does not produce $t$-tests or $p$-values for indirect effects. Instead, it produces bootstraps for the indirect effect and a 95\% confidence interval. Indirect paths are significant when the $95 \%$ confidence interval excludes zero; they are not significant when the 95\% confidence interval includes zero (Hayes, 2017; see Tables 3 and 4). 
Table 3

Model Summary of Indirect Effect of State Self-Objectification on Body Image Through Self-Esteem in Boys' Group $(n=64)$

\begin{tabular}{|c|c|c|c|c|c|c|}
\hline \multirow{3}{*}{ Predictors } & \multicolumn{6}{|c|}{ Outcome } \\
\hline & \multicolumn{3}{|c|}{ M-Self-esteem } & \multicolumn{3}{|c|}{$\mathrm{Y}$ - Body image } \\
\hline & $B$ & $S E B$ & $p$ & $B$ & $S E B$ & $p$ \\
\hline State self-objectification & -.16 & .05 & .001 & -.14 & .06 & .036 \\
\hline Self-esteem & - & - & - & .66 & .15 & .001 \\
\hline \multirow[t]{4}{*}{ Constant } & 36.34 & 1.81 & .001 & 7.46 & 6.06 & .22 \\
\hline & & $R^{2}=.15$ & & \multicolumn{3}{|c|}{$R^{2}=.37$} \\
\hline & & $\begin{array}{c}F(1,62)=11.28 \\
p<.001\end{array}$ & & \multicolumn{3}{|c|}{$\begin{array}{c}F(2,61)=17.61 \\
p<.001\end{array}$} \\
\hline & & & \multicolumn{4}{|c|}{$95 \%$ confidence interval } \\
\hline Indirect effect & $B$ & Boot $S E$ & Lower limit & \multicolumn{3}{|c|}{ Upper limit } \\
\hline Total effect & -.25 & .07 & -.38 & \multicolumn{3}{|c|}{-.11} \\
\hline Direct effect & -.14 & .06 & -.27 & \multicolumn{3}{|c|}{-.01} \\
\hline Indirect effect & -.11 & .05 & -.22 & \multicolumn{3}{|c|}{-.02} \\
\hline
\end{tabular}

\section{Table 4}

Model Summary of Indirect Effect of State Self-Objectification on Body Image Through Self-Esteem in Girls' Group $(n=71)$

\begin{tabular}{|c|c|c|c|c|c|c|}
\hline \multirow{3}{*}{ Predictors } & \multicolumn{6}{|c|}{ Outcome } \\
\hline & \multicolumn{3}{|c|}{ M - Self-esteem } & \multicolumn{3}{|c|}{ Y - Body image } \\
\hline & $B$ & $S E B$ & $p$ & $B$ & $S E B$ & $p$ \\
\hline State self-objectification & -.20 & .06 & .001 & -.10 & .07 & .143 \\
\hline Self-esteem & - & - & - & 1.01 & .13 & .001 \\
\hline \multirow[t]{4}{*}{ Constant } & 35.14 & 2.54 & .001 & 5.16 & 5.28 & .332 \\
\hline & & $R^{2}=.15$ & & \multicolumn{3}{|c|}{$R^{2}=.56$} \\
\hline & & $\begin{array}{c}F(1,69)=12.47 \\
p<.001\end{array}$ & & \multicolumn{3}{|c|}{$\begin{array}{c}F(2,68)=43.22 \\
p<.001\end{array}$} \\
\hline & & & \multicolumn{4}{|c|}{$95 \%$ confidence interval } \\
\hline Indirect effect & $B$ & Boot $S E$ & \multicolumn{2}{|l|}{ Lower limit } & \multicolumn{2}{|c|}{ Upper limit } \\
\hline Total effect & -.30 & .08 & \multicolumn{2}{|l|}{-.47} & \multicolumn{2}{|c|}{-.13} \\
\hline Direct effect & -.10 & .07 & \multicolumn{2}{|l|}{-.23} & \multicolumn{2}{|c|}{.03} \\
\hline Indirect effect & -.20 & .07 & \multicolumn{2}{|l|}{-.35} & \multicolumn{2}{|c|}{-.09} \\
\hline
\end{tabular}


In both groups of adolescents, state self-objectification was a significant predictor of self-esteem which, in its turn, had a significant impact on body image (see Figures 1 and 2) wherein this effect was much stronger in the group of girls.

Figure 1

Mediation Model Results in Boys 'Group (Standardized Coefficients)

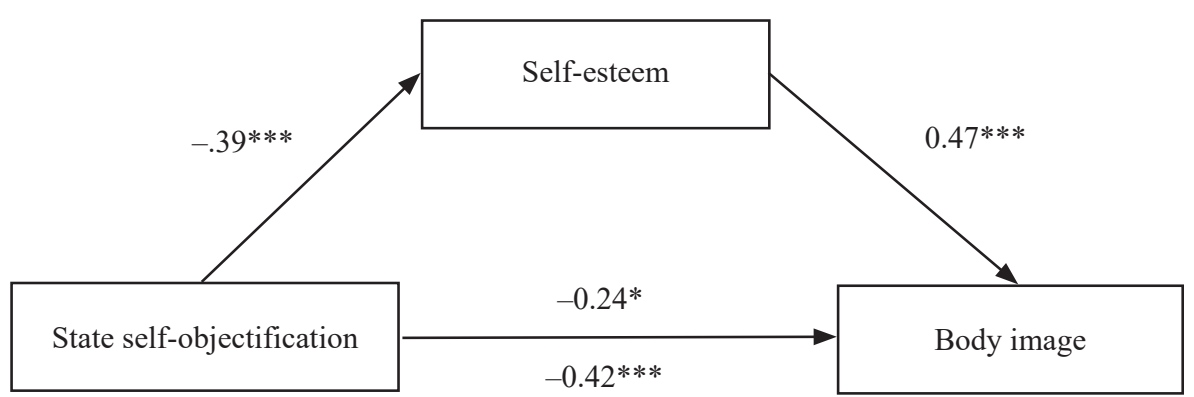

Figure 2

Mediation Model Results in Girls' Group (Standardized Coefficients)

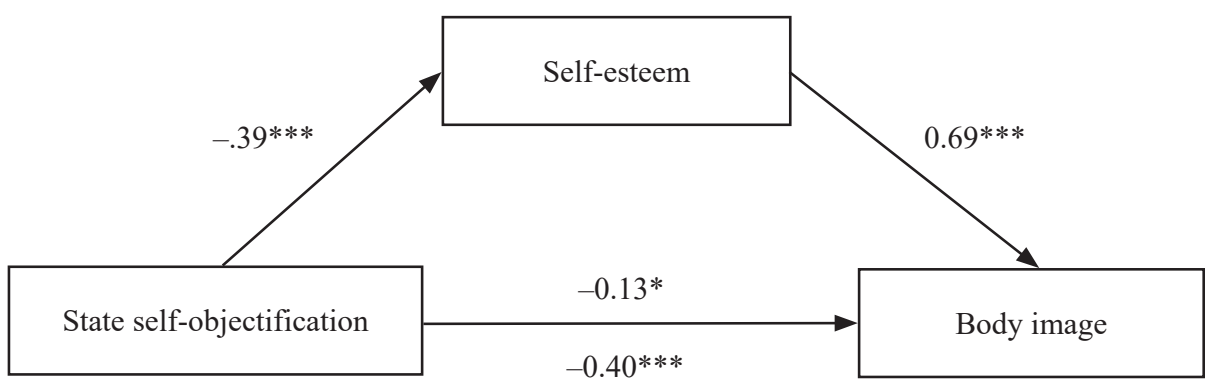

This means that the variable of self-esteem mediated the relationship between self-objectification state and body image. This indirect effect was significant and negative; in the group of girls the model of mediation produced a complete effect, whereas in the group of boys the mediation effect was partial. 


\section{DISCUSSION}

The present study explored the relationship between two variables: state selfobjectification and body image representation mediated by self-esteem in midadolescence. The preliminary analyses have revealed significant differences in the variables of interest between both sex groups of participants. The adolescent girls presented significantly lower scores in body image representation and selfesteem, which is also reflected in previous studies (Davison \& McCabe, 2006; Jones et al., 2004; McCabe \& Ricciardelli, 2001). At the same time, they showed a significantly higher level of self-objectification state, which means that the teenage girls (14-16 years old) in the laboratory-induced situation of being confronted with their own slightly distorted body image in the mirror have activated body evaluation processes much more strongly than the boys. This indicates a higher increase in the level of self-perception of the body as an object (i.e., self-objectification) in the adolescent girls than in the participating boys. The obtained results confirmed the previous findings according to which the girls are much more at the risk of self-objectification than boys in adolescence (Fredrickson \& Roberts, 1997; Martin \& Gentry, 1997).

The analytical highlight of the study was an examination of the remaining two hypotheses related to the mediation model with two predictors, self-objectification and self-esteem, and their impact on the mental representation of body image. The literature on the subject yields many correlation studies that confirm the relationships between self-objectification and self-esteem (e.g., Veldhuis et al., 2019) and between self-objectification and body image (e.g., Dryden \& Anderson, 2019), but to our knowledge there are no studies that have endeavored to identify the pathway by which self-objectification leads to body image in mid-adolescents. As anticipated, the hypothetical model of simple mediation found support in that self-objectification significantly predicted a decrease in self-esteem which in turn made a significant positive impact on body image. This means that self-esteem mediated significantly the relationship between the independent and the dependent variable, reducing the negative effect of self-objectification on the body image representation.

The present study provides some initial insights into a psychological mechanism behind the impact of a socially induced, objective body self-awareness on body image (e.g., the influence of the mass media and the advertisements in which female and male bodies are presented in an idealized form). The study demonstrated that the state of self-objectification had a direct, significant, and negative effect on body image. However, if the two variables of interests were mediated by selfesteem, the indirect effect became much weaker; although it was still significant in the boys' group (i.e., partial effect), but in the girls' group it proved insignificant 
(i.e., complete mediation). The results indicate that self-esteem plays an influential role in protecting positive body image in the Western societies, wherein not only young women but also boys are exposed to dangerous situations that activate selfobjectification, which reduces subjective body awareness. This protective role is part of the stream of research proving the role of self-esteem in some self-regulation processes (e.g., Baumeister et al., 1993). It is crucial to take preventive measures by strengthening adolescents' self-esteem with regard to the inner features instead of physical appearance. It is important especially in the case of girls because their body image constitutes a central reference point in self-definition (Thompson et al., 1999). Strengthening self-esteem should, however, take into account knowledge of its heterogeneity and be directed at improving those aspects that actually contribute to the well-being of a person (e.g., Baumeister et al., 2003). One of the goals of early educational intervention could be to help adolescents deconstruct advertising and media images (Clay et al., 2005) which, through reasoning processes, would enable them to disarm intrusive media messages and provide them with the skills of adequate self-assessment based on facts, and not on the acquired message.

\section{CReditT Author Statement}

Beata Mirucka (60\%): conceptualization, methodology, software, validation, formal analysis, resources, writing (original draft), supervision, writing (review and editing).

MoniKa KisielewSKa (40\%): conceptualization, methodology, investigation, resources, writing (original draft), writing (reviewing and editing).

\section{REFERENCES}

Assaiante, C., Barlaam, F., Cignetti, F., \& Vaugoyeau, M. (2014). Body schema building during childhood and adolescence: A neurosensory approach. Clinical Neurophysiology, 44(1), 3-12. https://doi.org/10.1016/j.neucli.2013.10.125

Baldwin, S. A., \& Hoffmann, J. P. (2002). The dynamics of self-esteem: A growth-curve analysis. Journal of Youth and Adolescence, 31, 101-113. https://doi.org/10.1023/A:1014065825598

Baumeister, R. F., Heatherton, T. F., \& Tice, D. M. (1993). When ego threats lead to self-regulation failure: Negative consequences of high self-esteem. Journal of Personality and Social Psychology, 64, 141-156. https://doi.org/10.1037/0022-3514.64.1.141

Baumeister, R. F., Campbell, J. D., Krueger, J. I., \& Vohs, K. D. (2003). Does high self-esteem cause better performance, interpersonal success, happiness, or healthier lifestyles? Psychological Science in Public Interest, 4(1), 1-44. https://doi.org/10.1111/1529-1006.01431 
Cash, T. F., \& Pruzinsky, T. (Eds.) (2002). Body Image: A handbook of theory, research, and clinical practice. Guilford Press.

Chung, J. M., Hutteman, R., van Aken, M. A. G., \& Denissen, J. J. A. (2017). High, low, and in between: Self-esteem development from middle childhood to young adulthood. Journal of Research in Personality, 70, 122-133. https://doi.org/10.1016/j.jrp.2017.07.001

Clay, D., Vignoles, V. L., \& Dittmar, H. (2005). Body image and self-esteem among adolescent girls: Testing the influence of sociocultural factors. Journal of Research on Adolescence, 15(4), 451-477. https://doi.org/10.1111/j.1532-7795.2005.00107.x

Dakanalis, A., Carrà, G., Calogero, R., Fida, R., Clerici, M., Zanetti, M. A., \& Riva, G. (2015). The developmental effects of media-ideal internalization and self-objectification processes on adolescents' negative body-feelings, dietary restraint, and binge eating. European Child \& Adolescent Psychiatry, 24(8), 997-1010. https://doi.org/10.1007/s00787-014-0649-1

Davison, T. E., \& McCabe, M. P. (2006). Adolescent body image and psychosocial functioning, Journal of Social Psychology, 146(1), 15-30. https://doi.org/10.3200/SOCP.146.1.15-30

Duarte, C., \& Pinto-Gouveia, J. (2017). Body image as a target of victimization by peers/parents: Development and validation of the Body Image Victimization Experiences Scale. Women \& Health, 57(9), 1061-1079. https://doi.org/10.1080/03630242.2016.1243603

Dryden, C., \& Anderson, J. (2019). The dark triad, trait-based self-objectification, and body image concerns in young women. Personality and Individual Differences, 145, 1-8. https://doi.org/10.1016/j.paid.2019.03.015

Eisenberg, M. E., Neumark-Sztainer, D., \& Paxton, S. (2006). Five-year change in body satisfaction among adolescents. Journal of Psychosomatic Research, 61, 521-527. https://doi.org/10.1016/j.jpsychores.2006.05.007

Fredrickson, B. L., \& Roberts, T. A. (1997). Objectification theory: Toward understanding women's lived experiences and mental health risks. Psychology of Women Quarterly, 21, 173-206. https://doi.org/10.1111/j.1471-6402.1997.tb00108.x

Fredrickson, B. L., Roberts, T. A., Noll, S. M., Quinn, D. M., \& Twenge, J. M. (1998). That swimsuit becomes you: Sex differences in self-objectification, restrained eating, and math performance. Journal of Personality and Social Psychology, 75, 269-284. https://doi.org/10.1037/00223514.75.1.269

Gallagher, S. (2005). How the body shapes the mind. Oxford University Press.

Gatti, E., Ionio, C., Traficante, D., \& Confalonieri, E. (2014). "I like my body; therefore, I like myself": How body image influences self-esteem - a cross-sectional study on Italian adolescents. Europe's Journal of Psychology, 10(2), 301-317. https://doi.org/10.5964/ejop.v10i2.703

Golan, M., Hagay, N., \& Tamir, S. (2014). Gender related differences in response to "in favor of myself" wellness program to enhance positive self and body image among adolescents. PLoS One, 9(3), e91778. https://doi.org/10.1371/journal.pone.0091778

Harter, S. (2012). Construction of the self: Developmental and sociocultural foundations (2nd ed.). Guilford Press.

Hayes, A. F. (2017). Introduction to mediation, moderation, and conditional process analysis: A regression-based approach (2nd ed.). Guilford Press.

Hayes, A. F. (2019). The PROCESS macro for SPSS, SAS, and R. https://www.processmacro.org/ download.html

Hayes, A. F., \& Preacher, K. J. (2014). Statistical mediation analysis with a multicategorical independent variable. British Journal of Mathematical and Statistical Psychology, 67(3), 451-470. https://doi.org/10.1111/bmsp.12028 
Hebl, M. R., King, E. B., \& Lin, J. (2004). The swimsuit becomes us all: Ethnicity, gender, and vulnerability to self-objectification. Personality and Social Psychology Bulletin, 30, 1322-1331. https://doi.org/10.1177/0146167204264052

Jones, D. C., Vigfusdottir, T. H., \& Lee, Y. (2004). Body image and the appearance culture among adolescent girls and boys: An examination of friend conversations, peer criticism, appearance magazines, and the internalization of appearance ideals. Journal of Adolescence Research, 19(3), 323-339. https://doi.org/10.1177/0743558403258847

Karsay, K., Knoll, J., \& Matthes, J. (2018). Sexualizing media use and self-objectification: A meta-analysis. Psychology of Women Quarterly, 42(1), 9-28. https://doi.org/10.1177/0361684317743019

Kling, K. C., Hyde, J. S., Showers, C. J., \& Buswell, B. N. (1999). Gender differences in self-esteem: A meta-analysis. Psychological Bulletin, 125, 470-500. https://doi.org/10.1037/00332909.125.4.470

Knauss, S., Paxton, S. J., \& Alsaker, F. D. (2008). Body dissatisfaction in adolescent boys and girls: Objectified body consciousness, internalization of the media body ideal and perceived pressure from media. Sex Roles, 59, 633-643. https://doi.org/10.1007/s10964-009-9500-2

Kostanski, M., \& Gullone, E. (1998). Adolescent body image dissatisfaction: Relationships with self-esteem, anxiety, and depression controlling for body mass. Journal of Child Psychology and Psychiatry, 39(2), 255-262. https://doi.org/10.1017/S0021963097001807

Kostanski, M., \& Gullone, E. (2007). The impact of teasing on children's body image. Journal of Child and Family Study, 16(3), 307-319. https://doi.org/10.1007/s10826-006-9087-0

Kostanski, M., Fisher, A., \& Gullone, E. (2004). Current conceptualisation of body image dissatisfaction: Have we got it wrong? Journal of Child Psychology and Psychiatry, 45(7), 1317-1325, https://doi.org/10.1111/j.1469-7610.2004.00315.x

Krueger, D. W. (2002). Integrating body self and psychological self: Creating a new story in psychoanalysis and psychotherapy. Brunner-Routledge.

Kuster, F., Orth, U., \& Meier, L. L. (2013). High self-esteem prospectively predicts better work conditions and outcomes. Social Psychological and Personality Science, 4, 668-675. https://doi.org/10.1177/1948550613479806

Łaguna, M., Lachowicz-Tabaczek, K., \& Dzwonkowska, I. (2007). Skala samooceny SES Morrisa Rosenberga - polska adaptacja metody [The Rosenberg Self-Esteem Scale: the Polish adaptation of the scale]. Psychologia Spoleczna, 2(02), 164-176.

Martin, M. C., \& Gentry, J. W. (1997). Stuck in the model trap: The effect of beautiful models in ads on female pre-adolescents and adolescents. Journal of Advertising, 26, 19-33. https://doi.org/10.1080/00913367.1997.10673520

McCabe, M. P., \& Ricciardelli, L. (2001). Parent, peer, and media influences on body image and strategies to both increase and decrease body size among adolescent boys and girls. Adolescence, $36(142), 225-240$.

McKenney, S. J., \& Bigler, R. S. (2016). Internalized sexualisation and its relation to sexualized appearance, body surveillance, and body shame among early adolescent girls. Journal of Early Adolescence, 36, 171-197. https://doi.org/10.1177/0272431614556889

McKinley, N. M., \& Hyde, J. S. (1996). The objectified body consciousness scale: development and validation. Psychology of Women Quarterly, 20, 181-215. https://doi.org/10.1111/j.1471-6402.1996.tb00467.x

Mirucka, B. (2017). A battery of tests of the body self representations. Przeglad Psychologiczny, 60(2), 263-282. 
Mirucka, B. (2018a). Podmiot ucieleśniony. Psychologiczna analiza reprezentacji ciała i tożsamości cielesnej [Subject embodied. A psychological analysis of body representations and body identity]. Scholar.

Mirucka, B. (2018b). The effect of experimental presentation of images of women in magazine advertising and works of art on body (dis)satisfaction in adolescent girls. Kultura i Edukacja, 2(120), 113-130. https://doi.org/10.15804/kie.2018.02.07

Morin, A. J. S., Maiano, C., Marsh, H. W., Janosz, M., \& Nagengast, B. (2011). The longitudinal interplay of adolescents' self-esteem and body image: A conditional autoregressive latent trajectory analysis. Multivariate Behavioral Research, 46(2), 157-201. https://doi.org/10.1080/00273171.2010.546731

Noll, S., \& Fredrickson, B. L. (1998). Mediational model linking self-objectification, body shame, and disordered eating. Psychology of Women Quarterly, 22, 623-636. https://doi.org/10.1111/j.1471-6402.1998.tb00181.x

Orth, U., \& Robins, R. W. (2014). The development of self-esteem. Current Directions in Psychological Science, 23, 381-387. https://doi.org/10.1177/0963721414547414

Orth, U., Robins, R. W., \& Widaman, K. F. (2012). Life-span development of self-esteem and its effects on important life outcomes. Journal of Personality and Social Psychology, 102, 12711288. https://doi.org/10.1037/a0025558

Paxton, S. J., Neumark-Sztainer, D., Hannan, P. J., \& Eisenberg, M. E. (2006). Body dissatisfaction prospectively predicts depressive mood and low self-esteem in adolescent girls and boys. Journal of Clinical Child \& Adolescent Psychology, 35(4), 539-549. https://doi.org/10.1207/s15374424jccp3504_5

Presnell, K., Bearman, S. K., \& Stice, E. (2004). Risk factors for body dissatisfaction in adolescent boys and girls: A prospective study. International Journal of Eating Disorders, 36, 389-401. https://doi.org/10.1002/eat.20045

Quinn, D. M., Kallen, R. W., Twenge, J. M., \& Fredrickson, B. L. (2006). The disruptive effect of self-objectification on performance. Psychology of Women Quarterly, 30, 59-64. https://doi.org/10.1111/j.1471-6402.2006.00262.x

Roberts, T. (2012). She is so pretty, she looks just like a Bratz doll!: Theoretical foundations for understanding girls and women's self-objectification. In E. L. Zurbriggen \& T. Roberts (Eds.), The sexualisation of girls and girlhood: Causes, consequences, and resistance (pp. 22-38). Oxford University Press.

Roberts, T. A., \& Gettman, J. Y. (2004). Mere exposure: Gender differences in the negative effects of priming a state of self-objectification. Sex Roles, 51, 17-27. https://doi.org/10.1023/B:SERS.0000032306.20462.22

Rodin, J., Silberstein, L., \& Striegel-Moore, R. (1984). Women and the weight: A normative discontent. In T. B. Sonderegger (Ed.), Psychology and gender (pp. 267-309). University of Nebraska Press.

Rosenberg, M. (1965). Society and the adolescent self-image. Princeton University Press.

Rousseau, A., \& Eggermont, S. (2017). Tween television and peers: Reinforcing social agents in early adolescents' body surveillance and self-objectification. Journal of Research on Adolescence, 28(4), 807-823. https://doi.org/10.1111/jora.12367

Rousseau, A., \& Eggermont, S. (2018). Media ideals and early adolescents' body image: Selective avoidance or selective exposure? Body Image, 26, 50-59. https://doi.org/10.1016/j.bodyim.2018.06.001

Smolak, L. (2004). Body image in children and adolescents: Where do we go from here? Body Image, 1, 15-28. https://doi.org/10.1016/S1740-1445(03)00008-1 
Thompson, J. K., \& Stice, E. (2001). Thin-ideal internalization: Mounting evidence for a new risk factor for body image disturbance and eating pathology. Current Directions in Psychological Science, 10, 181-183. https://doi.org/10.1111/1467-8721.00144

Thompson, J. K., Heinberg, L. J., Altabe, M., \& Tantleff-Dunn, S. (1999). Exacting beauty: Theory, assessment and treatment of body image disturbance. American Psychological Association.

Vandenbosch, L., \& Eggermont, S. (2015). The role of mass media in adolescents' sexual behaviors: Exploring the explanatory value of the three-step self-objectification process. Archives of Sexual Behavior, 44, 729-742. https://doi.org/10.1007/s10508-014-0292-4

Vandenbosch, L., \& Eggermont, S. (2012). Understanding sexual objectification: A comprehensive approach toward media exposure and girls internalization of beauty ideals, self-objectification and body surveillance. Journal of Communication, 62, 869-887. https://doi.org/10.1111/j.14602466.2012.01667.x

Veldhuis, J., Alleva, J. M., Bij de Vaate, A. J. D., Keijer, M., \& Konijn, E. A. (2019). Me, my selfie, and I: The relations between selfie behaviors, body image, self-objectification, and self-esteem in young women. Psychology of Popular Media, 9(1), 3-13. http://dx.doi.org/10.1037/ppm0000206

Vivar, K. L., \& Kruse, L. (2018). The impact of pediatric skin disease on self-esteem. International Journal of Women's Dermatology, 4, 27-31. https://doi.org/10.1016/j.ijwd.2017.11.002 